\title{
Morbid obese adults increased their sense of coherence I year after a patient education course: a longitudinal study
}

This article was published in the following Dove Press journal:

Journal of Multidisciplinary Healthcare

27 March 2015

Number of times this article has been viewed

\author{
May Solveig Fagermoen' \\ Glenys Hamilton ${ }^{2}$ \\ Anners Lerdal ${ }^{1,3}$ \\ 'Department of Nursing Science, \\ Institute of Health and Society, \\ University of Oslo, Oslo, Norway; \\ ${ }^{2} \mathrm{GAH}$ Consulting, Boston, MA, USA; \\ ${ }^{3}$ Department of Research, Lovisenberg \\ Diakonale Hospital, Oslo, Norway
}

Background: Personal factors are key elements to understand peoples' health behavior. Studies of such factors are important to develop targeted interventions to improve health. The main purpose of this study is to explore sense of coherence (SOC) in a sample of persons with morbid obesity before and after attending a patient education course and to explore the association between SOC and sociodemographic and other personal factors.

Methods: In this longitudinal purposely sampled study, the participants completed questionnaires on the first day of the course and 12 months after course completion. Sixty-eight participants had valid scores on the selected variables at follow-up: SOC, self-esteem, and self-efficacy. Relationships were assessed with correlation analyses and paired and independent samples $t$-tests and predictors with linear regression analyses.

Results: From baseline to follow-up, the total SOC score and the subdimension scores comprehensibility, manageability, and meaningfulness all increased significantly. At both time points, the SOC scores were low compared to the general population but similar to scores in other chronically ill. At baseline, a multivariate analysis showed that older age, having paid work, and higher self-esteem were directly related to higher total SOC score after controlling for other sociodemographic factors and the participants' level of self-efficacy. Multivariate analyses of the relationship between baseline predictors of SOC at 12-month follow-up, controlling for baseline SOC scores or sociodemographic or personal factors, revealed that none of these variables independently predicted SOC scores at follow-up.

Conclusion: The total SOC score and its subdimensions increased significantly at followup. SOC may be a useful outcome measure for lifestyle interventions in people with morbid obesity and possibly other health care problems. Subdimension scores may give an indication of what is poorly developed and needs strengthening. This might guide choices for targeted cognitive and psychosocial interventions. Further studies are needed to explore this issue with larger samples.

Keywords: obesity, health promotion, health behavior, self-efficacy, self-esteem

\section{Introduction}

Obesity is an increasing problem in the Western world, with implications for people's health as well as increasing the economic burden of providing care. ${ }^{1}$ Morbid obesity, ie, a body mass index of $40 \mathrm{~kg} / \mathrm{m}^{2}$ or greater, increases the risk of high blood pressure, diabetes, and cardiovascular disease (CVD) ${ }^{1-3}$ and is also associated with lower physiological and psychological well-being. ${ }^{4}$ Gaining an understanding of how to reduce risk factors for people with morbid obesity is crucial. Personal factors are one of five components identified as significant in understanding a person's health and behavior. ${ }^{5}$ Studies of personal factors and their possible changes over time are important in order
Correspondence: May Solveig Fagermoen Department of Nursing Science, Institute of Health and Society, University of Oslo, Nedre Ullevål 9, PO Box I I 30 Blindern, 0850 Oslo, Norway

Tel +4741234630

Fax +4722850590

Email m.s.fagermoen@medisin.uio.no 
to develop targeted interventions to improve people's health. In this study, the personal factors that were examined are sense of coherence (SOC), self-esteem, and self-efficacy. A recent study of people with morbid obesity found that health-related quality of life (HRQoL) was directly related to one's SOC even after controlling for sociodemographic variables, health behavior, environmental factors, and other personal factors. ${ }^{6}$

SOC is a concept introduced in Antonovsky's salutogenic theory where he argued health be seen as movement along a health (ease) - dis-ease continuum. ${ }^{7} \mathrm{He}$ defined SOC as "a global orientation that expresses the extent to which one has a pervasive, enduring though dynamic feeling of confidence", 7 also described as a "dispositional orientation toward life". SOC is comprised of three subdimensions: comprehensibility, manageability, and meaningfulness, considered respectively as cognitive, instrumental, and motivational components. Comprehensibility refers to the extent to which stimuli from one's internal and external environment is perceived as structured, predictable, and clear. Manageability refers to the extent to which the person perceives his/her internal and external resources as available and adequate to handle the demands posed by these stimuli. Meaningfulness reflects the extent to which the person sees these demands as challenges rather than burdens and worth investing energy and engagement. Antonovsky proposed that the "strength of one's SOC, [is] a significant factor in facilitating the movement toward health". ${ }^{8}$ A person with a strong SOC is more likely than a person with a weak SOC to define a stimulus as a nonstressor because he/ she is confident that things will work out well. ${ }^{9}$

Systematic reviews have concluded that Antonovsky's instruments to measure SOC are applicable to all cultures ${ }^{10}$ and that SOC has an impact on HRQoL ${ }^{11}$ and is a promising health-promoting resource that "strengthens resilience and develops a positive subjective state of health". ${ }^{12}$ Further, SOC was found to be associated with health behaviors ${ }^{13,14}$ and is applicable in the evaluation of patient education programs. ${ }^{15,16}$ Despite its relevance to health promotion, we have not been able to locate any studies that use SOC as an outcome measure among people with morbid obesity.

A course reflecting the ideas of a salutogenic approach is offered in some patient education resource centers in Norwegian hospitals. The course is mandatory for patients with morbid obesity who want surgical treatment and are referred by physicians. This course is grounded in cognitive behavior theory and emphasizes the participants' work in uncovering hidden resources and strengthening self-concept. Health care professionals in cooperation with previous course participants developed the content of the course. The major subjects include available treatments and their intended and unintended consequences and necessary lifestyle changes. Core methods are participants' use of an individual action plan, guided reflection, and participation in self-help groups, as well as physical activity. The course consists of 40 hours spread over 9-12 weeks. Course participation may positively influence SOC and other personal factors such as self-efficacy and self-esteem, ie, facilitating the participants' movement towards better health.

The main purpose of this study is to explore SOC in a sample of persons with morbid obesity before and after an educational course. The research questions are: Do sociodemographic variables and personal factors, self-esteem, and self-efficacy, relate to SOC and its subdimensions at baseline? Do any of the sociodemographic or personal factors at baseline predict SOC and its subdimensions at 12-month follow-up?

\section{Materials and methods \\ Study design and participants}

This study is part of a prospective longitudinal study with a within-subjects design exploring whether participation in the patient education course contributes to changes in HRQoL and testing several instruments with regard to their ability to detect change in personal factors over time. The present study included SOC, self-esteem, and self-efficacy instruments. Data were collected by means of questionnaires at the start of the course, and 2 weeks and 3, 6, and 12 months after course completion. However, due to low response rates at the intermediate time points, only data from baseline and 12-month follow-up were used in this study.

Participants were purposively sampled and recruited at three sites on the first day of ten identical mandatory courses held in the spring of 2009 in Eastern Norway. Follow-up data were collected by mailed questionnaires. Nonresponders received one reminder at each time point. All 185 course attendees were given verbal and written information about the study and invited to participate. Those consenting answered the questionnaire in a secluded room on-site and returned it in sealed envelopes later collected by the project representative. One hundred and forty-two people consented (77\%). The mean age of those who consented (42.5 years, standard deviation [SD]: 10.4) was not significantly different from those who did not (mean 44.2 years, SD: $9.1, t=-0.98$, $P=0.33, \mathrm{n}=43$ ). The proportion of women among the participants $(70.4 \%)$ was not significantly different from the rest of the course participants $\left(60.5 \%, \chi^{2}=1.51, d f=1, P=0.22\right)$. 
Missing scores in the indices were tolerated up to $20 \%$ and were replaced by the individual's mean response on the index. In the present study, the final sample consisted of 68 participants $(47.9 \%)$ with valid responses on all variables at baseline and 12-month follow-up.

\section{Sociodemographic variables}

Sociodemographic data included age (years), sex (male/ female), formal education ( $<13$ years, $\geq 13$ years) marital/ cohabitation status (married/not married), and employment status (working/not working).

\section{Sense of coherence}

This personal factor was assessed using the 13-item short version of Antonovsky's sense of coherence questionnaire (SOC-13). ${ }^{7}$ Respondents indicate agreement or disagreement to each item using a seven-point scale. Total scores ranged from 13 to 91, with higher scores reflecting a stronger SOC. The instrument consists of three subdimensions: comprehensibility (five items), manageability (four items), and meaningfulness (four items). The SOC-13 is a reliable and valid instrument. ${ }^{10}$ Cronbach's alpha ranged from 0.72 to 0.92 in prior studies and was 0.82 at baseline in our study. A Rasch analysis examining the psychometric properties of the SOC data showed that item \#1 did not have an acceptable goodness-of-fit and should not be included in the SOC total score. ${ }^{17}$ Accordingly, item \#1 was excluded and replaced with the mean of the three other items belonging to this subdimension (meaningfulness). The SOC total score and three subdimensions scores were calculated for each participant.

\section{Other personal factors}

The Rosenberg self-esteem scale (RSES) ${ }^{18}$ was used to assess participants' global self-esteem, which is an attitude associated with psychological well-being. ${ }^{19}$ The original RSES consists of ten statements with response options from 1 "strongly agree" to 4 "strongly disagree". We used a Norwegian abbreviated four-item version (RSES-4) developed by Ystgaard. ${ }^{20}$ The four items were selected by linear regression analysis and showed high correlation $(r=0.95)$ with the full ten-item version. The Cronbach's alpha of 0.85 for this study (at baseline) corresponded well with another Norwegian study. ${ }^{21}$ Total sum scores for the four-item version ranged from 4 to 16 , with higher scores representing higher self-esteem.

Self-efficacy is regarded as a coping resource and a strong sense of efficacy is related to better health and more social integration. ${ }^{22}$ The general self-efficacy scale (GSE) measures general optimistic self-belief in coping with the demands of life. ${ }^{23}$ The GSE consists of ten statements that the respondent rates on a scale from 1 "not at all true" to 4 "exactly true". The total score range is 10-40; higher scores reflect higher general self-efficacy. The GSE has been used in many countries and has shown good psychometric properties. ${ }^{23-25}$ At baseline in this study, Cronbach's alpha was 0.93 , indicating high internal consistency.

\section{Statistical analysis}

Associations among ordinal and categorical data were analyzed using chi-square tests. Group differences in the mean scores of continuous variables were evaluated with independent samples $t$-tests and differences between baseline and 12-month follow-up with paired-samples $t$-tests. Effect sizes were calculated on the differences between groups and the different time points according to Cohen's coefficient $d$; $d$ values $\geq 0.40$ were considered to be clinically significant. ${ }^{26}$ Cronbach's $\alpha$ was used to assess the internal consistency of the scales. The level of significance was set to $P>0.05$ and all tests were two-tailed. SPSS (v18.0 for Windows; SPSS Inc., Chicago, IL, USA) was used for the statistical analyses. ${ }^{27}$

The relationship between independent variables at baseline and scores on SOC total and the subdimensions at baseline and at 12-month follow-up were analyzed in separate linear regression analyses. In these analyses, all independent variables with a standardized $\beta$-value $\geq 0.20$ in bivariate analyses were included. Sociodemographic variables were included in step 1, and RSES-4 and GSE in step 2. When predicting the different SOC variables at 12-month follow-up, baseline scores for the same variables were included in step 3 (data not shown). Because all bivariate relationships between variables used in the analysis had a Pearson's correlation coefficient $r<0.7$, we determined that multicollinearity of variables was not an issue.

\section{Ethical issues}

Informed written consent was received from all participants. The Regional Medical Research Ethics Committee of Norway (REK Sør-Øst) and the Ombudsman of Oslo University Hospital approved the study (REK S-08662c 2008/17575; NCT 01336725).

\section{Results \\ Representativeness of the sample and attrition analyses}

The mean age of the participants with complete data at 12-month follow-up (43.4 years, SD: $10.3, \mathrm{n}=68$ ) did not 
differ significantly from the 74 participants who did not respond at 12-month follow-up or were excluded due to missing scores ("dropouts") (mean 41.6 years, SD: 10.6, $t=1.04, P=0.30, \mathrm{n}=74)$. The proportion of women in the study sample $(\mathrm{n}=51,75.0 \%)$ did not differ significantly from the proportion of women in the dropouts $\left(n=49,66.2 \%, \chi^{2}=1.31\right.$, $d f=1, P=0.25$ ). Analyses comparing the study sample and dropout sample on baseline indicated that the study sample had higher scores at baseline than the "dropouts" on SOC total (mean 54.7, SD: 11.5 vs mean 50.1, SD: $12.3 ; P=0.02$, $d=0.40)$, comprehensibility $(P=0.02, d=0.41)$, and meaningfulness $(P=0.05, d=0.32)$. No other significant differences were found between the two groups.

\section{Sociodemographic characteristics}

Sociodemographic characteristics and personal factors for the sample are presented in Table 1. At baseline, the mean age of the participants was 43.4 years. The majority were women $(75 \%)$. More men than women were working. No other differences with regard to sociodemographic variables were found.

\section{Sense of coherence}

The SOC total and subdimension scores at baseline and 12-month follow-up are shown in Table 2. No significant differences were found between men and women at either time point. The scores on SOC total and all subdimensions were significantly higher for the total sample and for the women at follow-up compared to baseline; the men had only significantly increased scores on comprehensibility at follow-up. The changes in total SOC scores and comprehensibility were clinically significant for the men and borderline for the total sample.

Bivariate correlations between variables at baseline and 12-month follow-up are shown in Table 3. At baseline, participants with higher age scored higher on manageability. Those with paid work reported higher scores on total SOC and both the manageability and meaningfulness subdimensions. Similarly, higher self-esteem and higher self-efficacy at baseline were related to higher baseline scores on total SOC and all subdimensions. In the analyses of personal factors at 12-month follow-up, having paid work at baseline was related to higher scores on total SOC and meaningfulness at 12-month follow-up. Self-esteem and self-efficacy scores at baseline were significantly associated with total SOC and all subdimension scores at 12-month follow-up, except that baseline self-efficacy was not significantly associated with manageability at follow-up.

The results of the linear regression analyses predicting baseline SOC total and subdimension scores are shown in Table 4. These revealed that controlling for sociodemographic and personal factors, higher total SOC and manageability scores were associated with older age, having paid work, and higher self-esteem. Meaningfulness was directly associated with both self-efficacy and self-esteem, and comprehensibility was only associated with self-esteem. Self-esteem was a particularly strong predictor and explained a relatively large proportion of the variance on all the SOC variables, reflecting the strong associations between these concepts. Multivariate analyses of the relationships between baseline predictors of SOC at 12-month follow-up, controlling for baseline SOC scores and sociodemographic and personal factors, revealed

Table I Sociodemographic characteristics and scores on personal factors at baseline

\begin{tabular}{|c|c|c|c|c|c|}
\hline \multirow[t]{2}{*}{ Sociodemographics } & \multirow{2}{*}{$\begin{array}{l}\text { All } \\
N=68 \\
N(\%)\end{array}$} & \multirow{2}{*}{$\begin{array}{l}\text { Men } \\
n=17 \\
n(\%)\end{array}$} & \multirow{2}{*}{$\begin{array}{l}\text { Women } \\
n=51\end{array}$} & \multirow{2}{*}{$\begin{array}{l}\text { Statistics } \\
\chi^{2}(\mathrm{~d} f)\end{array}$} & \multirow[t]{2}{*}{ P-value } \\
\hline & & & & & \\
\hline \multicolumn{6}{|l|}{ Level of formal education } \\
\hline $7-12$ years & $44(64.7)$ & $12(70.6)$ & $32(62.7)$ & $0.34(I)$ & 0.56 \\
\hline 13 years or higher & $24(35.3)$ & $5(29.4)$ & $19(37.3)$ & & \\
\hline \multicolumn{6}{|l|}{ Marital status } \\
\hline Married/cohabiting & $47(69.1)$ & $14(82.4)$ & $33(64.7)$ & $1.86(1)$ & 0.17 \\
\hline \multicolumn{6}{|l|}{ Employment status } \\
\hline \multirow[t]{2}{*}{ Paid work } & $46(67.6)$ & $15(88.2)$ & $31(60.8)$ & $4.39(I)$ & 0.04 \\
\hline & $M(S D)$ & $M(S D)$ & $M(S D)$ & $t$ & $P$-value \\
\hline Age (years) & $43.4(10.3)$ & $43.8(8.8)$ & $43.3(10.8)$ & 0.16 & 0.88 \\
\hline \multicolumn{6}{|l|}{ Personal factors } \\
\hline Self-esteem (scale 4-16) & $10.7(2.7)$ & II.2(2.3) & $10.5(2.8)$ & 1.10 & 0.28 \\
\hline Self-efficacy (scale I0-40) & $26.6(6.7)$ & $28.0(6.5)$ & $26.1(6.7)$ & 1.05 & 0.30 \\
\hline Sense of coherence (scale I3-9I) & $54.7(11.5)$ & $57.8(10.0)$ & 53.7 (II.9) & 1.41 & 0.17 \\
\hline
\end{tabular}

Note: Higher scores on self-esteem, self-efficacy, and sense of coherence represent higher levels of the respective variable.

Abbreviations: $M$, mean; SD, standard deviation. 

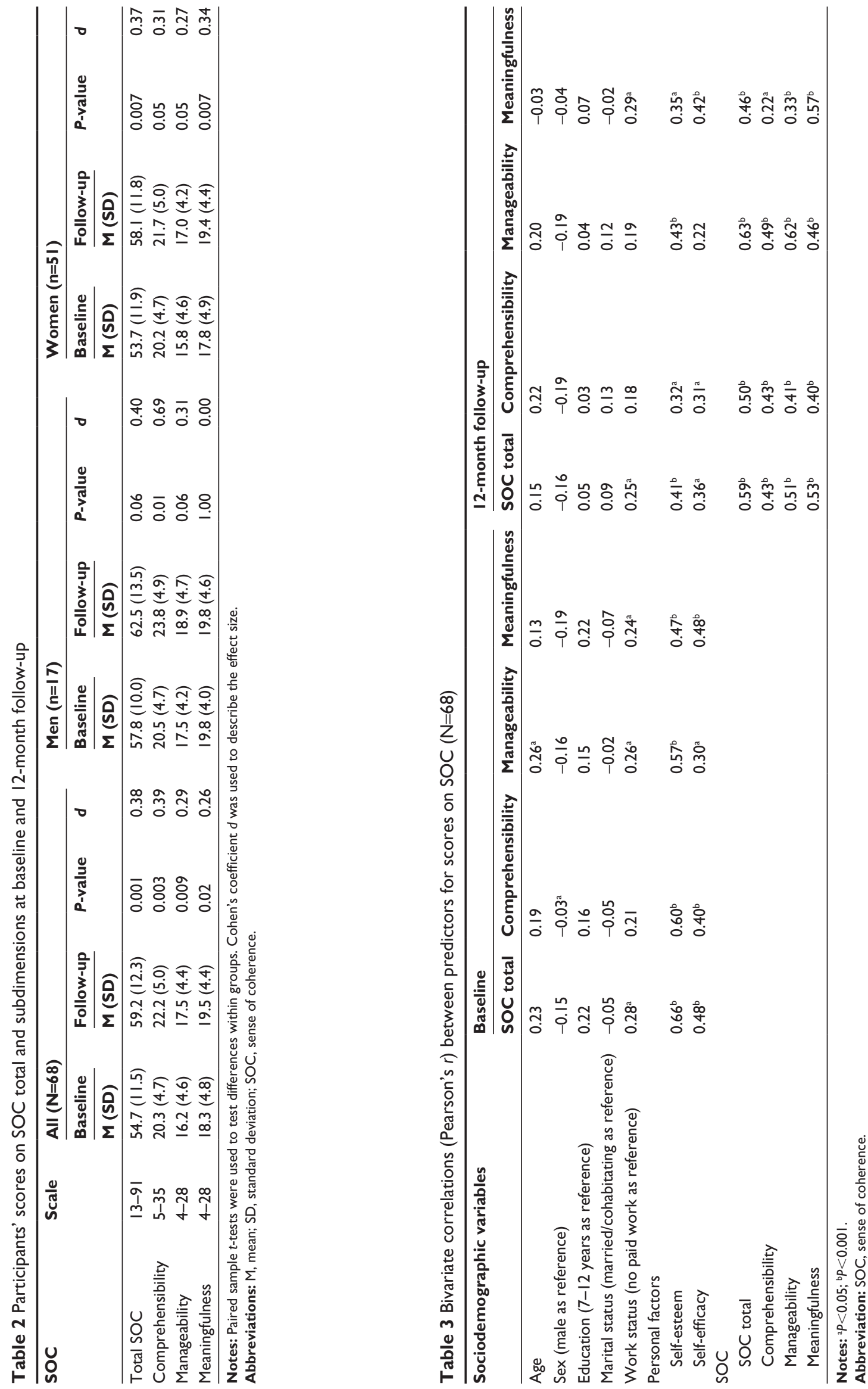
Table 4 Multivariate analyses of factors related to SOC total score and subdimension scores at baseline $(\mathrm{N}=68)$

\begin{tabular}{|c|c|c|c|c|c|c|c|c|}
\hline \multirow[t]{2}{*}{ Independent variables (baseline) } & \multicolumn{2}{|c|}{ SOC total score } & \multicolumn{2}{|c|}{ Comprehensibility } & \multicolumn{2}{|c|}{ Manageability } & \multicolumn{2}{|c|}{ Meaningfulness } \\
\hline & $\beta$ & P-value & $\beta$ & $P$-value & $\beta$ & $P$-value & $\beta$ & P-value \\
\hline \multicolumn{9}{|l|}{ Step I: sociodemographic variables } \\
\hline Age & 0.23 & 0.01 & - & - & 0.27 & 0.01 & - & - \\
\hline Education (7-12 years as reference) & 0.10 & 0.30 & - & - & - & - & 0.10 & 0.38 \\
\hline Work status (no paid work as reference) & 0.18 & 0.05 & 0.06 & 0.54 & 0.25 & 0.01 & 0.17 & 0.13 \\
\hline Explained variance $\left(R^{2}\right)$ & $19.0 \%$ & 0.003 & $3.9 \%$ & 0.11 & $20.0 \%$ & 0.001 & $11.1 \%$ & 0.022 \\
\hline \multicolumn{9}{|l|}{ Step 2: personal factors } \\
\hline Self-esteem & 0.55 & $<0.001$ & 0.53 & $<0.001$ & 0.51 & $<0.001$ & 0.28 & 0.02 \\
\hline Self-efficacy & 0.13 & 0.21 & 0.11 & 0.35 & -0.00 & 0.97 & 0.28 & 0.03 \\
\hline Change of variance ( $R^{2}-$ change) & 36.8 & $<0.001$ & $33.5 \%$ & $<0.001$ & $24.7 \%$ & $<0.001$ & $22.9 \%$ & $<0.001$ \\
\hline Explained variance $\left(R^{2}\right)$ & $55.8 \%$ & & $37.4 \%$ & & $44.7 \%$ & & $29.8 \%$ & \\
\hline
\end{tabular}

Notes: $\beta$ denotes standardized beta coefficients. There were four independent regression analyses. Abbreviation: SOC, sense of coherence.

that none of these variables independently predicted SOC total or subdimension scores at 12-month follow-up (data not shown).

\section{Discussion}

This study is, to our knowledge, the first to explore changes in SOC in a sample of individuals with morbid obesity. The results revealed that total SOC and all three subdimension scores significantly improved between baseline and 12 months after the educational course. The increase in scores was clinically significant for both the total SOC and the comprehensibility subdimension. At both time points, total SOC scores were low (mean 54.8 and 59.2) compared to other groups, such as Norwegian patients admitted to internal medical wards (mean 67.0$)^{28}$ and two Swedish general population samples with means of $68.5^{29}$ and $70.0 .{ }^{30}$ In a systematic review, only 16 of 131 studies (12\%) using the SOC-13 had scores below $60 .{ }^{31}$ These samples had health deficits such as poor health, psychiatric illness, or substance abuse. The low SOC total scores in our obese participants are thus in line with comparable groups with health problems. These findings reflect SOC's relation to health, ie, the strength of SOC is dependent on the resources a person possesses. ${ }^{8}$ Hence, in health promotion, an important aim is to strengthen the resources to increase the individual person's SOC.

Previous studies have reported changes in SOC after a structured intervention such as mindfulness training, lifestyle intervention, rehabilitation, and salutogenic treatment. Randomized controlled trials (RCTs) have shown clinically significant increases in SOC in people with: fibromyalgia ${ }^{32}$ and mental health problems. ${ }^{15,33}$ Longitudinal studies have also demonstrated SOC increases in people undergoing coronary bypass surgery ${ }^{34}$ and those with chronic musculoskeletal pain, ${ }^{35}$ breast cancer, ${ }^{36}$ myocardial infarction, ${ }^{37}$ psoriasis,${ }^{16}$ or depression..$^{38}$ All studies revealed SOC scores at baseline to be below the norm.

Antonovsky argued that there is no basis for deriving separate subscores for comprehensibility, manageability, and meaningfulness as these are 'inextricably intertwined'.$^{7(p 86)}$ However, due to the course content, we believed that the subdimensions might be affected differently over time. The analyses revealed increased mean scores on all three subdimensions during the 12-month follow-up with unequal levels of improvement. Previously, only a few studies have explored these subscores. Two longitudinal intervention studies have reported that manageability and/or comprehensibility increased after the interventions, while lesser change was observed in meaningfulness. ${ }^{15,34}$ This was also the case in our study. At our 1-year follow-up, comprehensibility had a borderline clinically significant effect size and meaningfulness showed the least change. The cognitive nature of both comprehensibility and manageability may make them more susceptible to change. ${ }^{39}$ The content and methods in the educational course in our study were cognitive in nature and theoretically targeted at the subdimensions, thus possibly increasing SOC. We argue that studying the subdimensions may provide deeper understanding of the relationship between changes in personal factors and improvement of health. Research results with regard to changes in the subdimensions may pose a challenge to Antonovsky's clear stand against measuring the subdimensions. ${ }^{79} \mathrm{He}$ did later state, however, that in order to promote health, one needs to analyze what ought to be done for persons suffering from a particular disability "[...] to strengthen the sense of comprehensibility, manageability and meaningfulness". ${ }^{8}$ In our view, these dimensions will have to be measured if one wants to know whether and how change occurs. 
With regard to the question about SOC and its relationship to other personal factors, baseline self-esteem had the strongest association with baseline SOC total and subdimension scores. This may reflect an overlapping definition of SOC and self-esteem, since both emphasize confidence in oneself. To our knowledge, Antonovsky did not directly address the concept of self-esteem in his definition of SOC, and further work is needed to more clearly distinguish these concepts. Despite the multivariate analyses showing associations between baseline SOC and several baseline sociodemographic and personal factors, none of these factors predicted the change in SOC scores at the 12-month follow-up, after controlling for baseline levels of SOC. Since there was a significant change in SOC and this was not predicted by sociodemographic nor the personal factors, our findings may indicate that $\mathrm{SOC}$ is an intrinsic relatively independent phenomenon. This provides support for Antonovsky's salutogenic theory.

We propose that strengthening SOC is a key strategy in health promotion in view of the documented link between SOC and health, ie, high SOC is associated with effective stress-coping and health, and low SOC is associated with poor health, both physical and mental. Regarding a weak SOC, Antonovsky suggested this may be enhanced when health personnel engage in client-centered encounters. However, improvements may be temporary since "the SOC of the adult is a deeply rooted, stable dispositional orientation of the person". ${ }^{7}$ One exception that may lead to significant and enduring changes, he argued, is planned interventions that equip persons "to seek out, within the scope of their lives, what I would call, SOC-enhancing experiences:". 7 Such an approach is reflected in the previously mentioned RCTs, ${ }^{15,32,33}$ including one that specifically designed the intervention in line with salutogenic principles..$^{15}$ These interventions had some basic commonalities: all were guided group sessions, and participants had a long-lasting health problem, met in groups to learn ways of coping, and were actively involved in group processes. Participants in our study attended a patient education course similar in context and methods. Additionally, empowering methods to strengthen self-esteem and improve coping with lifestyle changes were emphasized. Hence, the results from intervention studies appear to give some evidence to Antonovsky's suggestion, that SOC could be a dependent variable "to be shaped and manipulated so that it in turn can push people toward health". ${ }^{8}$ A recent study reported that SOC predicted health behaviors among patients with coronary heart disease $\mathrm{e}^{14}$ and another study of the relationship between health domains and SOC suggested this to be a relevant outcome variable in patients with chronic illness. ${ }^{40}$ We argue that focusing on SOC in health promotion is important both with regard to designing lifestyle interventions based on salutogenic principles and as an outcome variable.

\section{Strengths and limitations}

This study has a strong theoretical stance and used validated instruments developed from these theories. SOC, self-esteem, and self-efficacy are important concepts within the domain of personal factors and are highly relevant to people with morbid obesity. The prevalence of obesity is increasing rapidly worldwide; ${ }^{41}$ in Norway the prevalence is $23 \% .{ }^{42}$ In the International Classification of Functioning, Disability and Health (ICF) framework, ${ }^{5}$ personal factors are included as important aspects of people's health, and thus, are important to explore in relation to diseases such as morbid obesity. It is important to determine what interventions may contribute to positive changes related to coping with serious health problems. This follow-up study measured personal factors that influence health behavior and there was movement toward the healthy more positive direction of the continuum.

The sample was purposively collected from three different sites in Norway, and thus the associations reported are not specific to a single site. This study also had moderate attrition, as only half of the original baseline sample completed the 12-month follow-up and was included in this analysis. Given that the final sample had higher baseline scores than those who were excluded due to incomplete data, it is possible that these findings underrepresent participants with lower SOC scores.

The generalizability of this study is limited by the sample of convenience, which only represents attendees of a patient education course and by the unequal proportions of sex. The small sample increases the risk of type II errors. In future, greater effort should be made to enroll and retain subjects, particularly those with low SOC scores, to ensure a representative sample of this vulnerable population for which effective interventions are urgently needed.

Another limitation of the study is that attendees' weight before and after 12 months was not collected at the Patient Education Resource Centre, and thus, the role of weight loss could not be evaluated. There was also no comparison group included in this study, and thus, it cannot be determined whether the observed changes in SOC were specifically attributable to the patient education course. Future studies evaluating the effectiveness of such course to improve SOC and other health-related outcomes should be designed with an appropriate comparison group. 


\section{Conclusion}

In this study, the participants attended a patient education course based on a social cognitive approach with content and methods aimed at increasing knowledge and skills to promote actions toward a healthier life. The clinically significant changes in SOC observed from baseline to the 12-month follow-up indicate that the course may have a positive impact on the management of living with a longterm health problem. Furthermore, the study showed that the SOC instrument, including the subdimensions, is able to detect change over time. It remains to be seen whether the detected changes will be maintained. The results indicate that SOC may be a useful outcome measure for persons with morbid obesity and possibly persons with other chronic health problems. Subdimension scores may give an indication of what part of one's SOC is poorly developed and needs strengthening. This might guide choices for targeted cognitive and psychosocial interventions. For clinical purposes, we believe more research including SOC subdimensions is needed for persons with chronic illnesses exploring these interrelationships and their link to health, particularly RCTs and longitudinal cohort studies using repeated measures analyses, as well as studies with a larger sample.

\section{Acknowledgments}

The Norwegian Centre for Patient Education, Research and Service Development, Oslo, Norway funded this study. The authors alone are responsible for the content and writing of the paper.

\section{Disclosure}

The authors report no conflicts of interest in this work.

\section{References}

1. World Health Organization. Global Database on Body Mass Index. Geneva, Switzerland: World Health Organization; 2010. Available from: http://apps.who.int/bmi/index.jsp. Accessed February 12, 2015.

2. World Health Organization. Media Centre: Obesity and Overweight. Geneva, Switzerland: World Health Organization; 2015. Available from: http://www.who.int/mediacentre/factsheets/fs311/en/. Accessed February 25, 2015.

3. Dixon JB. The effect of obesity on health outcomes. Mol Cell Endocrinol. 2010;316(2):104-108.

4. Abilés V, Rodriguez-Ruiz S, Abilés J, et al. Psychological characteristics of morbidly obese candidates for bariatric surgery. Obes Surg. 2010;20(2):161-167.

5. World Health Organization. International Classification of Functioning, Disability and Health (ICF). Geneva, Switzerland: World Health Organization; 2001.

6. Lerdal A, Andenæs R, Bjørnsborg E, et al. Personal factors associated with health-related quality of life in persons with morbid obesity on treatment waiting lists in Norway. Qual Life Res. 2011;20(8): 1187-1196.
7. Antonovsky A. Unraveling the Mystery of Health: How People Manage Stress and Stay Well. San Francisco, CA: Jossey-Bass; 1987.

8. Antonovsky A. The salutogenic model as a theory to guide health promotion. Health Promot Int. 1996;11(1):11-18.

9. Antonovsky A. The structure and properties of the sense of coherence scale. Soc Sci Med. 1993;36(6):725-733.

10. Eriksson M, Lindström B. Validity of Antonovsky's sense of coherence scale: a systematic review. J Epidemiol Community Health. 2005;59(6): 460-466.

11. Eriksson M, Lindström B. Antonovsky's sense of coherence scale and its relation with quality of life: a systematic review. J Epidemiol Community Health. 2007;61(11):938-944.

12. Eriksson M, Lindström B. Antonovsky's sense of coherence scale and the relation with health: a systematic review. J Epidemiol Community Health. 2006;60(5):376-381.

13. Silarova B, Nagyova I, Rosenberger J, et al. Sense of coherence as a predictor of health-related behaviours among patients with coronary heart disease. Eur J Cardiovasc Nurs. 2013;13(4):345-356.

14. Myers V, Drory Y, Gerber Y; Israel Study Group on First Acute Myocardial Infarction. Sense of coherence predicts post-myocardial infarction trajectory of leisure time physical activity: a prospective cohort study. BMC Public Health. 2011;11:708.

15. Langeland E, Riise T, Hanestad BR, Nortvedt MW, Kristoffersen K, Wahl A. The effect of salutogenic treatment principles on coping with mental health problems: a randomised controlled trial. Patient Educ Couns. 2006;62(2):212-219.

16. Langeland E, Robinson HS, Moum T, Larsen MH, Krogstad AL, Wahl AK. Promoting sense of coherence: salutogenesis among people with psoriasis undergoing patient education in climate therapy. $B M C$ Psychol. 2013;1(1):11.

17. Lerdal A, Fagermoen MS, Bonsaksen T, Gay CL, Kottorp A. Rasch analysis of the sense of coherence scale in a sample of people with morbid obesity - a cross-sectional study. BMC Psychol. 2014;2:1.

18. Rosenberg M. Society and the Adolescent Self-Image. Princeton, NJ: Princeton University Press; 1965.

19. Rosenberg M, Schooler C, Schoenbach C, Rosenberg F. Global selfesteem and specific self-esteem: different concepts, different outcomes. Am Sociol Rev. 1995;60(1):141-157.

20. Ystgaard M. Sårbar Ungdom og Sosial Støtte. [Vulnerable Adolescents and Social Support]. Rapport no 1/93. Oslo, Norway: Senter for Sosialt Nettverk og Helse; 1993. [Norwegian].

21. Tambs K. Moderate effects of hearing loss on mental health and subjective well-being: results from the Nord-Trøndelag Hearing Loss Study. Psychosom Med. 2004;66(5):776-782.

22. Bandura A. Self-efficacy: The Exercise of Control. New York, NY: WH Freeman and Company; 1997.

23. Schwarzer R, Jerusalem M. Generalized self-efficacy scale. In: Weinman J, Wright S, Johnston M, editors. Measures in Health Psychology: A User's Portfolio. Causal and Control Beliefs. Windsor, UK: NFER-Nelson; 1995:35-37.

24. Schwarzer R, Scholz U. Cross-cultural assessment of coping resources: the general perceived self-efficacy scale. Paper presented at: The First Asian Congress of Health Psychology: Health Psychology and Culture; August 28-29, 2000; Tokyo: Japan.

25. Leganger A, Kraft P, Røysamb E. General task specific self-efficacy in health behavior research: conceptualization, measurements and correlates. Psychol Health. 2000;15(1):51-69.

26. Cohen J. A power primer. Psychol Bull. 1992;112(1):155-159.

27. SPSS Inc. SPSS for Windows (Version 18). Chicago, IL; 2010.

28. Veenstra M, Hofoss D. Patient experiences with information in a hospital setting: a multilevel approach. Med Care. 2003;41(4):490-499.

29. Nilsson KW, Leppert J, Simonsson B, Staarin B. Sense of coherence and psychological well-being: improvement with age. J Epidemiol Community Health. 2010;64(4):347-352.

30. Lindmark U, Stenström U, Gerdin EW, Hugoson A. The distribution of "sense of coherence" among Swedish adults: a quantitative crosssectional population study. Scand J Public Health. 2010;38(1):1-8. 
31. Eriksson M. Unraveling the Mystery of Salutogenesis. The Evidence Base of the Salutogenic Research as Measured by Antonovsky's Sense of Coherence Scale. Turku, Finland: Folkhälsan Research Centre, Health Promotion Programmes; 2007:1.

32. Weissbecker I, Salmon P, Studts JL, Floyd AR, Dedert EA, Sephton SE. Mindfulness-based stress reduction and sense of coherence among women with fibromyalgia. J Clin Psychol Med Settings. 2002;9(4):297-307.

33. Forsberg KA, Björkman, T, Sandman PO, Sandlund M. Influence of a lifestyle intervention among persons with a psychiatric disability: a cluster randomized controlled trial on symptoms, quality of life and sense of coherence. J Clin Nurs. 2010;19(11-12):1519-1528.

34. Karlsson E, Berglin E, Larsson PA. Sense of coherence: quality of life before and after coronary bypass surgery - a longitudinal study. $J A d v$ Nurs. 2000;31(6):1383-1392.

35. Lillefjell M, Jakobsen K. Sense of coherence as a predictor of work reentry following multidisciplinary rehabilitation for individuals with chronic musculoskeletal pain. J Occup Health Psychol. 2007;12(3): 222-231.

36. Dobkin PL. Mindfulness-based stress reduction: what processes are at work? Complement Ther Clin Pract. 2008;14(1):8-16.
37. Bergman E, Malm D, Karlsson JE, Berterö C. Longitudinal study of patients after myocardial infarction: sense of coherence, quality of life, and symptoms. Heart Lung. 2009;38(2):129-140.

38. Skärsäter I, Rayens MK, Peden A, et al. Sense of coherence and recovery from major depression: a 4-year follow-up. Arch Psychiatr Nurs. 2009;23(2):119-127.

39. Suominen S, Blomberg H, Helenius H, Koskenvuo M. Sense of coherence and health - does the association depend on resistance resources? A study of 3115 adults in Finland. Psychol Health. 1999;14(5): 937-948.

40. Veenstra M, Moum T, Røysamb E. Relationship between health domains and sense of coherence: a two-year cross-lagged study in patients with chronic illness. Qual Life Res. 2005;14(6):1455-1465.

41. Jeffery RW, Sherwood NE. Is the obesity epidemic exaggerated? No. BMJ. 2008;336(7638):245.

42. Holmen J, Midthjell K, Krokstad S, Holmen TL. Obesity and type 2 diabetes in Norway: new data from the HUNT study [abstract]. Obes Facts. 2009;2(4):256.
Journal of Multidisciplinary Healthcare

\section{Publish your work in this journal}

The Journal of Multidisciplinary Healthcare is an international, peerreviewed open-access journal that aims to represent and publish research in healthcare areas delivered by practitioners of different disciplines. This includes studies and reviews conducted by multidisciplinary teams as well as research which evaluates the results or conduct of such teams or health-

\section{Dovepress}

care processes in general. The journal covers a wide range of areas and welcomes submissions from practitioners at all levels, from all over the world. The manuscript management system is completely online and includes a very quick and fair peer-review system. Visit http://www.dovepress.com/ testimonials.php to read real quotes from published authors. 